\title{
8. The Paris Agreement on climate change: what legacy?
}

\section{Laurence Tubiana and Emmanuel Guérin}

The Paris Agreement on climate change was adopted in 2015 and entered into force in 2016 with the explicit intent of addressing the shortcomings of previous Multilateral Environmental Agreements (MEAs), building on the lessons learned from previous errors in crafting a truly global and effective climate agreement. It was also designed with a view to providing a durable but dynamic framework for reducing global greenhouse gas (GHG) emissions, building resilience to the effects of climate change, and reorienting financial flows and technological investments towards the objectives of climate change mitigation and adaptation.

Today, nationalism is on the rise and multilateralism is increasingly challenged as an approach to addressing global issues (trade, security, immigration, climate change, biodiversity losses) through international cooperation. At the same time, the need to increase the level of ambition of climate actions is also becoming even more pressing and urgent, to keep the objectives set by the Paris Agreement within reach and deliver on the promise for sustainable development more broadly (UN Environment, 2018). It is therefore more important than ever to better explain what the Paris Agreement really is, how it came to be, and how it can provide the basis for the necessary acceleration of climate actions.

Both of us actively took part in the negotiations of the Paris Agreement. ${ }^{1}$ Many people, from many different countries and backgrounds (representing countries, local authorities, civil society organizations, the business sector, workers and trade unions, the science and technological community, faith groups, indigenous peoples, the youth movement and many other individuals) can claim credit for the success of COP21 (Profiles of Paris, n.d.). Through this chapter, we would like to share our own perspective on the negotiations of this agreement, lay out the key concepts from international relations and global governance theories it builds onto, and briefly discuss some of the necessary next steps in light of the latest trends in global politics and climate science. 


\section{THEORETICAL FOUNDATIONS OF THE PARIS AGREEMENT}

\section{Sovereign Choices: Nationally Determined Contributions (NDCs)}

The theory of international agreements often distinguishes two broadly different types of agreements: bottom-up and top-down (Michaelowa, 2015). These two categories in fact contain several overlapping dimensions, including: "only" domestically legally binding commitments vs internationally legally binding ones (with sanctions in the case of non-compliance); and voluntary commitments (i.e., self-determined contributions) vs commitments based on an explicit formula for sharing the global costs (or "burden") and benefits.

Reality is, as always, more subtle and more complex. The Paris Agreement could be described as a hybrid between a top-down and a bottom-up approach, even if it leans more towards a bottom-up approach. But the distinction between top-down and bottom-up agreements is nonetheless useful, even in practice, because it captures the trade-off negotiators inevitably face between: participation (the main concern of those in favour of bottom-up approaches); and effectiveness (the key objective of those arguing for top-down approaches) (Raustiala, 2005).

At the centre of the Paris Agreement lies the concept of NDCs. NDCs are the vehicle for all countries to attach to the agreement itself their contributions in terms of climate change mitigation and adaptation; and, in the case of developed countries, their contributions to the needs of developing countries for climate finance, technology and capacity building.

From the start, it was made very clear that the agreement itself (which includes the collective long-term goals for climate actions, the rules and principles for individual contributions, the transparency system and the cooperation mechanisms) and the NDCs were both part of the Paris Agreement "package", but also clearly separate: because they have a different legal status (the framework agreement being internationally legally binding - even if it does not include sanctions in the case of non-compliance, while the NDCs are "only" domestically legally binding), but also because they have a different timeframe (the framework agreement being open ended and not time bound, while the NDCs are to 2025 or 2030 and need to be periodically revised and enhanced).

Several considerations prevailed to make a clear distinction between the framework agreement and the NDCs. Chief among them was the willingness, shared by all parties, to design an agreement that would make it possible for the US to join without requiring a two-thirds majority vote from its Senate. Hence the clear distinction between the obligation for the US (and every other country) to submit an NDC as part of the Paris Agreement; and the voluntary 
commitment to reach a particular target for reducing its GHG emissions (and provide a specific amount of finance to developing countries) (Roberts \& Arellano, 2017).

But the distinction between the legal status of the framework agreement and the NDCs was not just a way of taking into consideration the particular circumstances of the US. In fact, it is a concern that was also shared by most emerging countries, including China and India (unlike the European Union, the Least Developed Countries [LDCs] and the Small Island and Developing States [SIDS], which did not have an issue with taking an internationally legally binding commitment to reduce their GHG emissions).

In fact, the major concern for most developing countries participating in a multilateral system, whose design they had often played no part in, was and still is the protection of their national sovereignty. Negotiations in Copenhagen at COP15 demonstrated how anxious developing countries' governments and non-governmental organizations (NGOs) were about the external imposition of norms on their own policy and development space. The assumption at that time was that the distribution of the remaining carbon budget limited by definition their capacity to grow on the same development path. Protection of sovereignty was even mentioned in the final Copenhagen text drafted in December 2009 between a number of emerging countries and the US as a desperate attempt to find a common ground.

Any global policy instrument, and in particular the idea of a global carbon market, was perceived as a breach of that protective fence, as was the notion of a global agreement constraining emissions. The Paris framework had to respond to that fundamental anxiety to ensure a broad participation, building on the assumption that perception of interests will evolve over time as the risk of climate change will become more evident to all and that responses to it look increasingly workable and beneficial. The Paris Agreement was conceived from the start as a learning process betting on the power of ideas diffusion and narrative performance.

The need to make it crystal clear to countries, in particular those especially wary of their sovereignty, that they would not face international sanctions if they did not meet their domestic commitment to reduce their GHG emissions, was not the only reason for treating the framework agreement and the NDCs differently. Another reason was to make it plainly obvious that they had different timeframes: the framework agreement was here to stay, while the NDCs were to be periodically revised and enhanced (as we will discuss in further detail below).

Before the adoption of the Paris Agreement, the efforts of the international climate community were indeed almost entirely consumed in the endless negotiation and renegotiation of international agreements (the United Nations Framework Convention on Climate Change [UNFCCC] was adopted as early 
as 1992; the Kyoto Protocol, which the US never ratified, was then signed in 1997; the climate negotiation process derailed in Copenhagen in 2009, when it failed to reach a global deal; it was rescued one year later in Cancun; etc.) (Center for Climate and Energy Solutions, n.d.). The objective at COP21 was to make sure that the process would deliver a durable framework (i.e., one that does not have to be renegotiated all the time and is therefore flexible enough) to make it possible to concentrate efforts after that on the much more important objectives of actually reducing GHG emissions, adapting to climate change, and reorienting financial flows and technological investment towards these goals.

\section{A Clear Long-term Goal: Zero GHG Emissions}

Bottom-up contributions by nation-states are, by definition, insufficient to address a global issue. And the Paris Agreement would be of limited use, if any, if it did not do more than simply capture self-determined contributions by countries. The value of international cooperation is precisely to unlock collective action that amounts to more than the sum of its parts. One of the most important contributions of the Paris Agreement is in fact, for the first time, to lay out a clear collective long-term goal for reducing global GHG emissions and addressing climate change more broadly (Carbon Brief, 2015).

The ways in which the international community has expressed this long-term goal has evolved over time (Gao, Gao \& Zhang, 2017). This evolution reflects both the tension between politics and science, and the difficulty for countries (but also simply for people) to face the individual consequences of what they are ready to accept as a necessary (and mutually beneficial) collective objective, but also the evolution of climate science itself (the functioning of the climate system, the nature and magnitude of climate impacts in different scenarios of GHG emission concentrations, and the costs and benefits of the different mitigation options).

Before the Paris Agreement, the agreed long-term goal for reducing global GHG emissions (as included in the Cancun Agreement, 2010) was to reduce them at a level consistent with an increase in average temperatures maintained below $2^{\circ} \mathrm{C}$ compared to pre-industrial levels. The Paris Agreement made an important contribution to both the level of ambition and degree of precision of this goal.

First, the Paris Agreement states that the objective is to limit the average increase in temperatures compared to pre-industrial levels "to well below $2^{\circ} \mathrm{C}$, aiming for $1.5^{\circ} \mathrm{C}$ ". The explicit mention of $1.5^{\circ} \mathrm{C}$ as an aspirational objective is an important step forward, in particular for the LDCs and SIDS (i.e., those contributing the least and suffering the most from climate change) who have long demanded that this is the stated goal of climate actions. The Intergovernmental 
Panel on Climate Change (IPCC) Special Report (SR) on $1.5^{\circ} \mathrm{C}$ (IPCC, 2018), mandated by Paris decisions, provided much detail as to the great differences of impacts between the $1.5^{\circ} \mathrm{C}$ and $2^{\circ} \mathrm{C}$ average temperature increase scenarios, as well as the global GHG emission reduction pathways consistent with the $1.5^{\circ} \mathrm{C}$ objective.

Second, the Paris Agreement also spells out clearly, for the first time, the global GHG emission reduction pathways consistent with these average temperature increase limits. In particular, it clearly states that the objective is to achieve "the balance between GHG emission sources and sinks" (i.e., net-zero GHG emissions) during the second half of the century. Since then, the IPCC $1.5^{\circ} \mathrm{C}$ SR clarified that: in order to limit the average temperature increase to below $2^{\circ} \mathrm{C}$, global $\mathrm{GHG}$ emissions need to reach net zero by 2085 (global $\mathrm{CO}_{2}$ energy- and industry-related emissions by 2070); and to limit the average temperature increase to $1.5^{\circ} \mathrm{C}$, global GHG emissions need to reach net zero by 2070 (global $\mathrm{CO}_{2}$ energy- and industry-related emissions by 2050).

Being clear about the fact that global GHG emissions need to reach net zero (before they have to turn net negative) to stick to the objectives of the Paris Agreement (in fact, to any given average temperature increase objective) dramatically changed the debate (if not yet the actions) on climate mitigation. The fact that, given that human-induced climate change is correlated to the stock of global GHG emissions (and not their flow), global GHG emissions have to stay within a given global carbon budget in order not to exceed a certain level of average temperature increase, is something that was well known for a long time by climate scientists. But the fact that the objective of climate change mitigation is now framed in the public discourse as "zero emissions" has profound impacts on how to approach GHG emission reduction strategies.

Before that, every country (or every sector within a country) entered into the debate by arguing why others should do more (because they had contributed more historically; because they had higher per-capita or per-GDP GHG emissions; because it was more cost effective to reduce GHG emissions in other sectors, etc.). Now, even if the timing of reaching net-zero GHG emissions arguably has to be different for different countries and sectors, this has become the ultimate objective for all. Moving away from an incremental deviation from business-as-usual and burden-sharing approaches towards a shared vision for a net-zero economy and society is probably the most important contribution from the Paris Agreement to the narrative of climate action. From there every action or policy will have to be evaluated against this benchmark. As so often happens, this key result was not at the core of the trade-offs on which negotiators were debating: more time was dedicated to arguing on the level of responsibility of nations or X than on the global goal of the regime. 


\section{A Periodic Assessment and Increase of Short-term Actions}

Although the Paris Agreement clearly spells out the global GHG emission reduction pathways consistent with the objective of limiting the average temperature increase well below $2^{\circ} \mathrm{C}$, aiming for $1.5^{\circ} \mathrm{C}$, the NDCs made by countries at COP21 and attached to the agreement are inconsistent with these pathways. And the difference between the projected level of global GHG emissions in 2030 (provided NDCs are fully implemented) and the level consistent with a well below $2^{\circ} \mathrm{C}$ or $1.5^{\circ} \mathrm{C}$ emission reduction pathway is not small: the gap is between 13 and $15 \mathrm{Gt}$ of $\mathrm{CO}_{2}$ equivalent for a well below $2^{\circ} \mathrm{C}$ scenario; and between 29 and $32 \mathrm{Gt}$ of $\mathrm{CO}_{2}$ equivalent for a $1.5^{\circ} \mathrm{C}$ scenario. As a reference, the level of GHG emission today is slightly higher than $50 \mathrm{Gt}$ of $\mathrm{CO}_{2}$ equivalent (UNEP, 2018).

By and large, what is needed is therefore an increase by a factor of three or so of the level of ambition of the current NDCs to 2030. The NDCs pledged at COP21 do not even achieve a peaking of global GHG emissions in 2030, when they need to peak by around 2020 to keep the option open of achieving the goals set by the Paris Agreement.

There are two ways to look at the discrepancy between the sum of NDCs and the global GHG emission reduction pathways consistent with the objective of limiting the average temperature increase well below $2{ }^{\circ} \mathrm{C}$, aiming for $1.5^{\circ} \mathrm{C}$. The first is to consider that the Paris Agreement is intrinsically flawed because of this gap (Lowe, 2018); that countries are fundamentally incapable of facing the individual consequences of their collective choices; and that the Paris Agreement is insufficient at best, maybe useless altogether, to address effectively the issue of climate change (Cass, 2015).

The dissonance between the ambition of the collective long-term goal and the modesty of short-term individual actions, as well as the rhetoric between self-proclaimed climate leadership by some and the reality of their climate actions, is indeed profoundly worrying and should be challenged. We are running out of time to address climate change, which would come at great costs not just for the environment or the economy but also simply for people's lives; and the window of opportunity to keep open the option of delivering on the objectives set at COP 21 is closing fast. But this is precisely why the Paris Agreement includes a mechanism for the periodic review and assessment of the adequacy of NDCs compared to the long-term goal, every five years. And the first of these moments, when NDCs need to be revised and enhanced, comes up in 2020.

The first - unexpected - test for the Paris Agreement was the US decision to withdraw. The fact that no other countries, including China, withdrew following the US decision, proved the resilience of the Paris Agreement, as well as the failed attempts at G20 and G7 to erase the reference to the Paris 
Agreement. But the resilience of the Paris Agreement to such a big shock, although it is a necessary condition for its durability and therefore its effectiveness in the long run, is certainly not a guarantee of its ability to deliver the necessary global GHG emission reductions in the short term. And the real test for the effectiveness of the Paris Agreement in addressing climate change will be its ability to deliver a significant increase in the level of ambition of the current NDCs in 2020.

\section{Decarbonization Strategies: The Link Between Bottom-up and Top-down Approaches}

To progressively close this gap, the NDC increase in 2020 needs to be guided by the ultimate objective of reaching net-zero GHG emissions. The Paris Agreement contains an important - although sometimes overlooked - provision, inviting countries to submit a 2050 decarbonization strategy (2050 Pathways Platform, n.d.) ("long-term low-GHG development strategy") before 2020.

Not much attention was paid in the run-up to COP21 to the issue of 2050 decarbonization strategies. It was mainly an issue for the scientific community (Deep Decarbonization Pathways Project, n.d.), while the negotiations by countries and the pressure from civil society concentrated on the issues of NDCs and the long-term goal. The reason why we insisted so much to include this provision in the agreement is because we knew these 2050 decarbonization strategies would provide the missing link between: the fundamentally bottom-up nature of an agreement based on self-determined contributions and the necessary top-down nature of an agreement aimed at keeping GHG emissions within a global carbon budget.

For a long time, climate negotiations stumbled over the obstacle of agreeing on a "burden-sharing" formula (i.e., a recipe that would establish by how much countries need to reduce their GHG emissions by when, so that each country would do its fair share of the global effort). No negotiation was able to find the magic number that could satisfy justice criteria, in particular taking into account the enormous quantity of $\mathrm{CO}_{2}$ stock in the atmosphere due to the emissions of industrialized countries over two centuries, and could be safe from the point of view of the carbon budget left.

In addition, climate actions were framed as a cost and the purpose of the international negotiations was to share this cost equally across countries. This approach reached an impasse, not only because of the lack of incentives for countries to engage in cooperation to share a cost, but also because of their inescapably conflicting views over the criteria to be chosen for the equitable sharing of the global carbon budget (historical emissions; current or pro- 
jected emissions; per-capita or per-GDP emissions; least-cost options, etc.) (Cameron, 2012).

NDCs provided a response to the impossibility of agreeing on a burden-sharing formula. But of course, they do not provide a solution to the fact that they need to add up to a certain level of global GHG emissions reduction. 2050 decarbonization strategies provide a possible way out (Hare et al., n.d.). Not a perfect one, at least from the point of view of making sure that they add up to the necessary level of global GHG emissions reduction, which would require agreeing on a burden-sharing formula as well (an elusive task from a political perspective), but certainly a second best in the suboptimal world of global politics and definitely an improvement to the pure bottom-up world of NDCs.

Indeed, if reducing GHG emissions entails short-term costs, ${ }^{2}$ it yields benefits in the long run. Looking at 2050 as the horizon for decarbonization strategies - as opposed to 2025 or 2030 only - therefore shifts the terms of the debate from short-term opportunity costs to long-term development opportunities. It also makes the co-benefits (or rather, the primary benefits) of climate actions (energy security, food security, jobs, air quality, technological innovation, etc.) much more visible (The New Climate Economy, n.d.).

There is no easy answer to the question of what countries' 2050 target for reducing their GHG emissions should be. But the fact that, collectively, all countries have to reach net-zero GHG emissions during the second half of the century makes it possible to define a simple rule of thumb: high-income countries should reach net-zero GHG around 2050; middle-income countries around 2060; and low-income countries around 2070. This simple rule should not be interpreted as a straightjacket, and the fact that countries embark on an exercise to design their long-term development strategies (in the sectors of energy, industry, buildings, transport, agriculture, etc.), guided by the objective of reaching net-zero GHG emissions at some point during the second half of the century ${ }^{3}$ is more important - at least at first - than insisting on a particular date. It means clearly that every country has to design a low- and then zero-carbon path, and that the carbon market (i.e., buying emissions reductions where they are less costly) is not a long-term solution.

\section{Beyond Nation-states: The Role of Non-state Actors (NSAs)}

As sovereignty protection is a red line for many countries in a world where no clear hegemon can operate, enforcement mechanisms are a major challenge in any international agreement. This was a very strong argument for involving NSAs actors in the preparation process and to consider them as powerful levers of implementation. The Paris Agreement can be considered as an innovation in terms of global governance is because of the central role played by NSAs. 
Associating NSAs as observers to the design of an international agreement - or even in some cases as implementers - is not an innovation as such. Since the first UN Environment and Development Conference in 1992, known as the Earth Summit, nine Major Groups and other Stakeholders (MGoS) participate, in different ways, to the UN processes on sustainable development (Sustainable Development Knowledge Platform, n.d.): women, children and youth, indigenous people, NGOs, local authorities, workers and trade unions, business and industry, scientific and technological community, farmers. But in the case of the Paris Agreement, they played a much more active and central role than in many other international processes (Hale, 2018). Local authorities (cities, regions and states) and businesses (including investors) were particularly key, not just to encourage countries to adopt a global climate deal or make sure their concerns were addressed (direct access to finance, competitiveness, etc.) the way they traditionally do, but because they also took commitments of their own to reduce their GHG emissions, improve resilience to climate change, mobilize climate finance and divest from high-carbon assets, and invest in low-carbon technology deployment and innovation.

The contribution to the Paris Agreement "package" was explicitly recognized, encouraged and organized within the Climate Action Agenda (UNFCCC, n.d.). The objective was twofold:

\section{Catastrophism vs agency}

First, to create a positive narrative around climate action and to demonstrate, through concrete actions and commitments on the ground by local authorities, to businesses and investors that climate actions could be an opportunity and yield benefits, that they were not just a constraint or a cost. The importance attached to narratives, and of the role to be played by NSAs to create a positive narrative came from the realization of the limitations of catastrophism as a trigger for action. It is well established by now by social psychology that, even if the risks are well understood and the threats perceived as great and imminent, people need agency to act. The Climate Action Agenda was designed with this purpose in mind, and not just as a framework to encourage individual commitments from NSAs, but also to communicate around them as a whole.

\section{Rational expectations and self-fulfilling prophecies}

Beyond the need to create a positive narrative and to provide agency to NSA willing to take actions and make commitments, the Climate Action Agenda was therefore conceived as a way to shape expectations that the transition to a zero-GHG and climate-resilient future was not only necessary (a point well established by the scientific community a long time ago), not just beneficial (a point consistently stressed by NGOs for a long time also), but also inevi- 
table, already well underway, and poised to accelerate; and therefore, that the early movers would reap its benefits while the laggards would bear the costs (We Mean Business Coalition, 2015).

\section{The Climate Regime: A Regime Complex}

The Paris Agreement is therefore very different from the traditional type of international agreement among nation-states. And beyond the fact that the agreement is largely bottom-up in nature, because it is based on self-determined contributions, the fact that it involved so many different stakeholders in its design, who now have a stake in its continuation and implementation, surely explains why it proved resilient to the US withdrawal. The We Are Still In movement (We Are Still In, n.d.) in the US, which gathers the US states, cities, businesses and investors committed to the implementation of the Paris Agreement and climate action more broadly (and will hopefully provide the

political basis for the US to re-enter the Paris Agreement after the end of Trump's mandate) is a direct application at the federal level of the method that was applied globally with success at COP21.

In the language of international relations theory, the global climate regime would therefore be called a regime complex (Keohane \& Victor, 2010). The idea is that there is not a single institution, or even a single process, governing the global response to climate change. The Paris Agreement is, arguably, the centre of this regime complex. But the Montreal Protocol plays a vital role in progressively phasing out a specific GHG: hydrofluorocarbon. GHG emissions from international aviation and shipping, because they are global in nature, require a special treatment within the context of their respective organizations (International Civil Aviation Authority and International Maritime Organization). It has started, even if far too slowly, but already major shipping companies are committing to net-zero emissions by 2050.

The Major Economies Forum (MEF), initiated by George W. Bush as a substitute to UN negotiations, ended up playing a very useful complementary role to the UN process under the Obama administration. But precisely, these other approaches - and probably others to be designed - are a complement, not a substitute, to the Paris Agreement as a global framework agreement.

\section{THE LEGACY OF THE PARIS AGREEMENT: A PLATFORM FOR THE ACCELERATION OF CLIMATE ACTIONS}

No text can deliver action per se. But a text, with clear goals and milestones, approved by so many countries, supported by so many constituencies from businesses to cities, NGOs, labour unions, financial institutions and even 
climate activists, is a platform that can act as a reference and accelerate action. Activists already use it to sue governments, by shareholders to question management strategies of companies' boards and, to vote, and increasingly by financial actors to measure the risks of their portfolios.

In 2020, the first year of implementation of Paris Agreement, all governments have to present improved climate plans for 2030 and long-term strategies for 2050. Diplomatic pressure, mobilization of actors inside countries, international financial institutions, will help force the major emitters to be consistent with their commitments.

Already the Paris goals, that is, going to net-zero emissions by 2050 or soon after, are spreading beyond governments' plans. Not only have a number of countries (as of today 114) committed to be carbon neutral or even climate neutral by 2050, but local authorities, cities and subnational entities, businesses and financial actors are doing it as well. A reality check is needed to test how serious these commitments are. A way to ensure credibility, a condition to change beliefs and mindsets, is to engage around clear plans and roadmaps as much as short-term decisions consistent with Paris goals.

The legacy of Paris relies on the capacity of its logic and goals to be transmittable to all sectors of activity. This "contamination" is proving effective as even actors that are by definition not bound by any intergovernmental treaty are internalizing the Paris Agreement in their strategies and objectives. Progressively, the Paris norms are seen as undeniable.

This normalization process is crucial as a founding block of peer pressure, the only enforcement mechanism of the Paris Agreement. Peer pressure is clearly a very weak mechanism but it is the only mechanism we have in international law. But this weakness can be transformed into a much stronger force if the pressure comes from all fronts, inside countries and outside, outside businesses and inside, and so on.

Then, of course, these norms have to be transmitted into the realm of policies in countries, across sectors, investment, tax, industry, innovation, labour, trade, fiscal, agriculture, and so forth. The transformation of the regulatory framework will operate the real implementation of Paris Agreement. Because of this normalization, some countries have already started the process, in Europe and elsewhere.

But the implementation of the Paris agreement has to go beyond governments and organized constituencies and interests. The scope and breath of the transformation required to eliminate fossil fuels needs the buy-in of a broad range of actors in the societies. The legacy of the Paris Agreement will be secured if citizens consider a zero-carbon future as a positive endeavour, a development prospect that responds to their concerns. It means that the Paris goals have to be embedded in a broad social compact where the relations between human societies and nature are rebalanced. The Paris Agreement 
cannot be implemented from the top only. Forcing societies to shift through imposition of policies from governments without consultation and participation of citizens in the decision-making will create insuperable oppositions. Social justice has to go hand in hand with deep climate action. This is the real test for the Paris Agreement.

\section{NOTES}

1. To the extent that countries, in particular low emitters, are happy to join an agreement where large emitters self-determine their contribution to the global effort.

2. Investment costs, or transition costs.

3. And revise their GHG emission reduction target for 2025 or 2030 based on this strategy.

\section{REFERENCES}

Cameron, E. (2012). What is equity in the context of climate negotiations? WRI.org, 14 December. Accessed 6 April 2020 at https://www.wri.org/blog/2012/12/what-equity -context-climate-negotiations.

Carbon Brief (2015). Explainer: The long-term goal of the Paris climate deal. Accessed 6 April 2020 at https://www.carbonbrief.org/explainer-the-long-term-goal-of-the -paris-climate-deal.

Cass, O. (2015). Why the Paris climate deal is meaningless. Politico.eu, 29 November. Accessed 6 April 2020 at https://www.politico.eu/article/paris-climate-deal-is -meaningless-cop21-emissions-china-obama/.

Center for Climate and Energy Solutions (n.d.). History of UN climate talks. Accessed 6 April 2020 at https://www.c2es.org/content/history-of-un-climate-talks/.

Deep Decarbonization Pathways Project (DDPP) (n.d.) [website]. Accessed 6 April 2020 at http://deepdecarbonization.org/.

Gao, Y., Gao, X., \& Zhang, X. (2017). The $2{ }^{\circ} \mathrm{C}$ global temperature target and the evolution of the long-term goal of addressing climate change - from the United Nations Framework Convention on Climate Change to the Paris Agreement. Engineering, $3(2), 272-8$.

Hale, T. (2018). The Role of Sub-state and Non-state Actors in International Climate Processes. London: Energy, Environment and Resources Department, Royal Institute of International Affairs.

Hare, B., Ancygier, A., De Marez, L., \& Yanguas Parra, P. (n.d.). Facilitating global transition: the role of nationally determined contributions in meeting the long-term temperature goal of the Paris Agreement. Accessed 6 April 2020 at http://ndcpartnership.org/facilitating-global-transition-role-nationally-determined -contributions-meeting-long-term.

Intergovernmental Panel on Climate Change (IPCC) (2018). Global Warming of $1.5^{\circ} \mathrm{C}$ : An IPCC Special Report. Accessed 6 April 2020 at https://www.ipcc.ch/sr15/.

Keohane, R.O., \& Victor, D.G. (2010). The regime complex for climate change. Harvard Discussion Papers, No. 10-33. The Harvard Project on International Climate Agreements.

Lowe, T. (2018). The Paris Climate Accords are even more useless than you thought. Washington Examiner, 15 December. Accessed 6 April 2020 at https:// 
www.washingtonexaminer.com/opinion/the-paris-climate-accords-are-even-more -useless-than-you-thought.

Michaelowa, A. (2015). Overview and assessment of international climate policy architectures and scenarios. Climatepolicyinfohub.eu, 18 February. Accessed 6 April 2020 at https://climatepolicyinfohub.eu/international-climate-policy-architectures$\%$ E2\%80\%93-top-down-and-bottom.

Profiles of Paris. (n.d.). Profiles. Accessed 6 April 2020 at https://profilesofparis.com/ profiles/.

Raustiala, K. (2005). Form and substance in international agreements. American Journal of International Law, 99, 581-614.

Roberts, T., \& Arellano, A. (2017). Is the Paris climate deal legally binding or not? Climatechangenews.com. Accessed 6 April 2020 at https://www.climatechangenews .com/2017/11/02/paris-climate-deal-legally-binding-not/.

Sustainable Development Knowledge Platform (n.d.). About Major Groups and other Stakeholders. Accessed 6 April 2020 at https://sustainabledevelopment.un.org/ aboutmajorgroups.html.

The New Climate Economy (n.d.). The Global Commission on the Economy and Climate [website]. Accessed 6 April 2020 at https://newclimateeconomy.net/.

2050 Pathways Platform (n.d.) [website]. Accessed 6 April 2020 at https://www .2050pathways.org/.

UN Environment (2018). Emissions Gap Report 2018. Accessed 6 April 2020 at http:// www.unenvironment.org/resources/emissions-gap-report-2018.

United Nations Framework Convention on Climate Change (UNFCCC) (n.d.). Global Climate Action [website]. Accessed 6 April 2020 at https://climateaction.unfccc.int.

We Are Still In (n.d.) [website]. Accessed 6 April 2020 at https://www.wearestillin .com/.

We Mean Business Coalition (2015). Business leaders: Paris Agreement will accelerate shift to thriving, clean global economy [blog]. Accessed 6 April 2020 at https:// www.wemeanbusinesscoalition.org/blog/business-leaders-paris-agreement-will -accelerate-shift-to-thriving-clean-global-economy/. 